\title{
Effective Clinical Teaching Practice and Associated Factors Among Midwifery Educators in Public Universities of Ethiopia: Institution-Based Cross-Sectional Study
}

\section{Kebenesa Angasu Kitaba (D) Solomon Weldemariam iD ${ }^{2}$ Abate Bekele Belachew iD ${ }^{3}$ Tariku Bekela' \\ 'School of Midwifery, Faculty of Health Sciences, Institute of Health, Jimma University, Jimma, Ethiopia; ${ }^{2}$ Department of Midwifery, College of Health Sciences, Mekelle University, Mekelle, Ethiopia; ${ }^{3}$ School of Public Health, College of Medicine and Health Sciences, Arba Minch University, Arba Minch, Ethiopia}

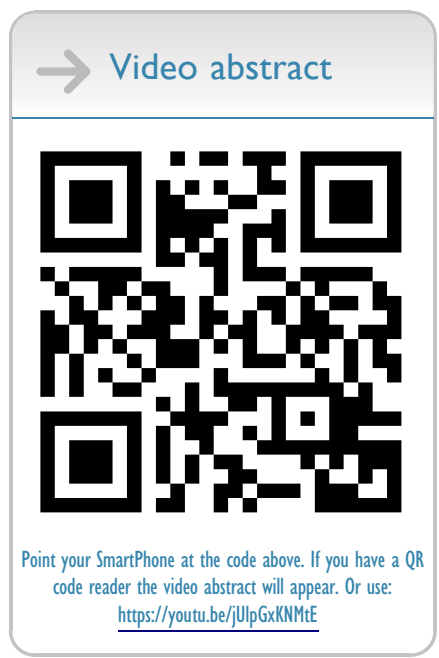

Correspondence: Kebenesa Angasu Kitaba

Tel +251919841766

Email kebenesa2019@gmail.com
Background: Although effective clinical teaching realistically improves learners to be competent, in Ethiopia only $31.6 \%$ of midwifery graduates have passed the national proficiency standard for graduation. Likewise, research evidence is lacking on effective clinical teaching practice of midwifery educators in Ethiopia.

Objective: This study aimed to assess effective clinical teaching practice and associated factors among midwifery educators in public universities of Ethiopia.

Methods: Institution-based cross-sectional study was conducted in April 2019 on 424 midwifery educators selected by simple random sampling technique. Data were collected through email by using a semi-structured, pretested, self-administered questionnaire, entered into Epi-data version 4.2, and analyzed by SPSS version 23. Bivariate and multivariable logistic regression analyses were done to test the association. The odds ratio at $95 \%$ confidence interval (CI) and P-value $<0.05$ were used to ascertain statistical significance.

Results: Only 178 (47.3\%) of participants had effective clinical teaching practice. Clinical teaching experience $(\mathrm{AOR}=4.72 ; 95 \% \mathrm{CI}=1.97,11.29)$, training on higher diploma in teaching profession $(\mathrm{AOR}=2.78 ; 95 \% \mathrm{CI}=1.61,4.82)$, clinical teaching workshop (AOR=4; $95 \% \mathrm{CI}=1.98,8.05)$, students per clinical unit $(\mathrm{AOR}=3.71 ; 95 \% \mathrm{CI}=1.66,8.26)$, giving objectives of clinical learning for students $(\mathrm{AOR}=4.74 ; 95 \% \mathrm{CI}=2.43,9.25)$, using performance-based assessment tool ( $\mathrm{AOR}=1.82 ; 95 \% \mathrm{CI}=1.04,3.16)$ and having good interest in clinical teaching $(\mathrm{AOR}=8.63 ; 95 \% \mathrm{CI}=2.91,25.56)$ were factors positively associated with effective clinical teaching practice.

Conclusion: Less than half of midwifery educators of Ethiopian Public Universities had effective clinical teaching practice. The educators' clinical teaching experience, training, and adherence to clinical teaching standards were identified to affect effective clinical teaching positively. Therefore, educators should adhere to the standards for effective clinical teaching and receive training on effective teaching.

Keywords: effective teaching, midwifery educators, public universities, Ethiopia

\section{Background}

Midwifery is a profession concerned with the provision of holistic care for women during maternal life, for newborns, and infants. ${ }^{1}$ Ability to perform midwifery competency in real situations cannot be achieved through classroom learning alone. $^{2}$ Thus, the preponderance of clinical experience in the training of midwifery students cannot be undervalued. It is noteworthy in guiding the midwifery 
education process. $^{3}$ To enable midwifery students to acquire intended clinical experience, effective clinical teaching (ECT) is compulsory. ${ }^{4}$ But the quality and competence of midwifery graduates are affected by the excellence and capability of midwifery educators to teach effectively. $^{5}$

Midwifery educators should deliver ECT that optimally facilitate students' learning. ${ }^{6}$ These include consistently performing ECT attributes such as establishing rapport with learners, and maximizing the use of case-based learning opportunities, being knowledgeable, providing support, role modeling, being clinically competent, knowing how to teach and being communicative. ${ }^{6-9}$

ECT builds students' clinical knowledge, skill, attitude, critical thinking, clinical judgment, and decision-making ability. ${ }^{4}$ Accordingly, ECT can lead to the fulfillment of the 5th Ethiopian educational sector development plan for educational relevance and quality improvement in the midwifery context. This is to produce demand-driven and competent midwifery graduates. ${ }^{10}$ In line with this, ECT can be one strategy through which the third (Ensure healthy lives and promote wellbeing for all at all ages) sustainable development goal (SDG) can be achieved thereby improving the competence of health workers leading to better patient outcome. ${ }^{11}$

Ethiopia is a developing country committed to expanding equitable access to quality tertiary education. ${ }^{10,12,13}$ But the graduation rate of students by first-degree from a university is as low as $79 \%$ partly due to low quality of instruction. ${ }^{10}$ Even among midwifery diploma and firstdegree graduates, only $31.6 \%$ passed the national standard ( $\geq 60 \%$ ) of competence for graduation in 2013 after examined at the point of their graduation which leads to failure to satisfy the country's demand for competent and qualified midwifery professionals. ${ }^{14}$

Related studies done previously were focused on describing how frequently each effective clinical teaching attribute was implemented by clinical educators. ${ }^{4,15-17}$ Besides, none of these studies identified factors associated with effective clinical teaching practice (ECTP). However, the current study was aimed to identify factors associated with ECTP using regression analysis. Hence, the findings contribute new knowledge on ECTP among midwifery educators in public universities of Ethiopia. Also, it helps midwifery educators to maximize ECTP and so does the competency of midwifery graduates that can satisfy the demand for competent midwifery professionals. Moreover, it establishes baseline information for further study. Lastly, it serves as a springboard for stakeholders to deal with the problem.

\section{Methods}

\section{Study Design and Period}

An institution-based cross-sectional study was employed from April 1 to 30, 2019.

\section{Study Setting}

In Ethiopia, by the time this study was conducted, there were 47 Ethiopian Public Universities (EPU) distributed in all regions of the country. Of these 47 EPU, only 30 of them were selected for this study with the criteria of having had Midwifery Education Program (MEP) and had started teaching midwifery clinical courses. Specifically, these 30 EPU are three (Adigrat, Aksum, and Mekelle) universities from the Tigray region; Seven (Bahir Dar, Debre Birhan, Debre Markos, and Debre Tabor, Gondar, Woldiya, and Wollo) universities from Amhara region; Eight (Ambo, Arsi, Bulehora, Haramaya, Jimma, Madawalabu, Metu, and Wollega) universities from Oromia region; seven (Arba Minch, Dilla, Hawassa, Mizan-Tepi, Wachamo, Welkite, and Wolayita Sodo) universities from South Nation, Nationalities and Peoples region; and the rest five are as follows: Addis Ababa University found in Addis Ababa federal city administration which is the capital city of the country; Dire Dawa University located in Dire Dawa federal city administration; Samara University located in Afar region; Jigjiga University located in the Somali region and Assosa University located in Benishangul Gumuz region. These 30 EPU had 807 midwifery educators of whom 584 of them are male. At the data collection period, 502 midwifery educators were active staff while the rest 279 were learning their master's degree and 26 were learning their doctorate of philosophy degree.

\section{Study Population}

All midwifery educators recruited as regular academic staff in the $30 \mathrm{EPU}$ for the position of graduate assistant II and above who taught at least one clinical course within this (2018/2019) and/or last (2017/2018) academic year were the study population. Midwifery educators who were learning their master's degree or doctorate of philosophy were excluded from this study since they were on education, their response could probably be the result of the education they were learning but may not be what they practice during their clinical teaching. On the other hand, since they might be busy 
with their study, the concern they give for such extra responsibility may be low and may not provide their response.

\section{Sample Size Determination and Sampling Technique}

The sample size was calculated using single population proportion formula $\left(\mathrm{n}=(\mathrm{z} \alpha / 2)^{2} \mathrm{p}(1-\mathrm{p}) / \mathrm{d}^{2}\right)$ with the assumption of (50\%) proportion of ECTP, $95 \%$ confidence level, $5 \%$ level of precision and $10 \%$ of non-response rate resulting 424 final sample size. The sample size was proportionally allocated for the $30 \mathrm{EPU}$ using the sampling frame taken from the midwifery department of respective universities. Finally, a simple random sampling technique was used to select study participants.

\section{Operational Definition Effective Clinical Teaching Practice}

Was defined as practicing qualities that enable clinical educators to teach effectively. These qualities include teaching abilities, clinical competence; learning evaluation, interpersonal relationship, and personality of clinical educator those facilitate clinical learning of students.

\section{Effective Clinical Teaching Practice Scale}

ECTP was measured using 47 items pointed out of five based on how frequently (1 "never", 2 "rarely", 3 "sometimes", 4 "nearly always", 5 "always") each quality were practiced during clinical teaching. The sum of the score was used to classify the status of ECTP of respondents using $75 \%$ as cut point as EPU use it as criteria for effective teaching. As an example, the legislation of Jimma University was referenced. ${ }^{18}$ As a result, respondents that had a sum of score $\geq 188(75 \%)$ were considered as having ECTP, and those who had a sum of score $<188$ (75\%) were considered as having not ECTP.

\section{Performance-Based Assessment Tool}

Is objective structured clinical examination (OSCE), rubrics, and/or checklist used to assess how well students perform midwifery clinical skills.

\section{Pretest}

The pretest was done on $43(10 \%)$ of the sample size among nurse educators of Jimma University before the actual study. The purpose of the pretest was to test the validity and reliability of the questionnaire and to check the wording, logic, and order of the questions. Finally, the questionnaire was found valid based on expert review of the questionnaire and reliable with Cronbach's alpha coefficient 0.88 which shows good internal consistency and modification was made concerning the syntax of the questionnaire accordingly. The experts who checked the validity of the questionnaire were two Ph.D. holders and three masters' holders' senior clinical teachers of midwifery at Mekelle University. They reviewed the questionnaire and also used the pretest data as supportive of their review and confirmed the validity of the questionnaire.

\section{Data Collection Procedures} Instrument

A semi-structured questionnaire partially developed and partially adopted from the previous study was used for data collection. We developed part of the questionnaire that encompass independent variables by incorporating both locally relevant factors that were not studied previously and factors identified by different studies conducted elsewhere. ${ }^{19-22}$ To do this we determined the variables depending on the objective of the study; followed by formulating, sequencing, formatting the questions, and finally, we pre-tested as part of the whole questionnaire. The part of the questionnaire used to measure the outcome variable was adopted from the clinical teachers' effectiveness inventory tool developed by Mogan \& Knox. ${ }^{15}$ It was reported valid and reliable in reviewed literature. ${ }^{4,15}$ The questionnaire contains six sections: socio-demographic characteristics seven questions, in-service training status twelve questions, clinical teaching site characteristics five questions, faculty characteristics five questions, and self-reported attributes of respondents toward clinical teaching five questions. Section six was the adopted part used to measure ECTP of respondents by 47 items that describe characteristics of ECT. The questionnaire was developed in English and did not translate to the local language as respondents were university midwifery educators and they were considered as they understand English as it is the official working language at a university level in the country.

\section{Data Collection Method}

Data were collected through email. In the beginning, the head midwifery department of the respective EPU was informed through a phone call about the study and its data collection method. They were also requested for forwarding the questionnaire to their staff members who were selected randomly to participate in the study after asking 
them for written informed consent to participate in the study by themselves. As a result, the response of all head midwifery departments of EPU was ok. Then, the questionnaire and a polite introductory letter were emailed for them. The polite introductory letter describes the purpose of the study, inclusion criteria, the way how to fill the questionnaire and submit it back directly to the principal investigator with the deadline of submission date and contact address.

\section{Data Quality Control}

To assure the quality of data, we used pretested, valid, and reliable questionnaire to collect data. The objective of the study and strict assurance of their response confidentiality was clarified for participants to encourage them to provide their genuine response. Finally, the authors checked the filled questionnaire for completeness, consistency and coded it.

\section{Data Analysis}

Checked and coded data were entered on Epi-data version 4.2 and exported to SPSS version 23 for analysis. Bivariate analysis was done to test the crude association of predictors with ECTP. Variables having p-values $\leq 0.2$ on bivariate analysis were included in multivariable logistic regression analysis and factors associated with ECTP were determined. The odds ratio at 95\% CI was used to measure the statistical association. P-values less than 0.05 were used to determine the statistical significance. Finally, the results were presented by table and text.

\section{Ethical Consideration}

This study was conducted in accordance with the declaration of Helsinki. Practically, ethical approval was obtained from the institutional ethical review board of Mekelle University College of Health Sciences with protocol number: ERC 1243/2019. A support letter was obtained from the department of midwifery. Both ethical approval and support letter were submitted to the respective head midwifery department of the 30 EPU. Each study subject was informed about the purpose, benefit, risk, confidentiality of their response through information provided on the participant information sheet, and written informed consent was obtained.

\section{Results}

\section{Socio-Demographic Characteristics of Respondents}

In this study, 376 midwifery educators were participated making a response rate of $88.7 \%$. Around four-fifths 298 $(79.3 \%)$ of respondents were male. While the median age was 30 with interquartile range (the first and third quartiles) was 27 and 32 years, respectively (Table 1).

\section{In-Service Training Status of Respondents} Just more than three-fourth 292 (77.7\%), of respondents, were trained on basic effective teaching skill, trained on a higher diploma in the teaching profession (HDP), and had clinical teaching workshop respectively. But, nearly all $367(97.6 \%)$ of respondents were not trained on the training of trainers of effective teaching skill.

\section{Clinical Teaching Site Characteristics}

More than two-fifth $166(44.2 \%)$ of respondents teach clinical courses where students were learning in the same clinical teaching site at the same time from five

Table I Socio-Demographic Characteristics of Midwifery Educators of Ethiopian Public Universities, Ethiopia, 2019 $(\mathrm{N}=376)$

\begin{tabular}{|l|l|l|l|}
\hline Variables & Category & Frequency & $\begin{array}{l}\text { Percent } \\
\text { (\%) }\end{array}$ \\
\hline Age in years & $\leq 24$ & 21 & 5.6 \\
& $25-34$ & 323 & 85.9 \\
$\geq 35$ & 32 & 8.5 \\
\hline Marital status & Married & 263 & 69.9 \\
& Single & 113 & 30.1 \\
\hline Professional qualification & BSc & 98 & 26.1 \\
& MSc & 278 & 73.9 \\
\hline Clinical experience before & None & 148 & 39.4 \\
becoming academic staff (in & $<2$ & 82 & 21.8 \\
years) & $\geq 2$ & 146 & 38.8 \\
\hline Clinical teaching & $\leq 1$ & 81 & 21.5 \\
experience (in years) & $\mathrm{I}-3$ & 160 & 42.6 \\
& $4-6$ & 119 & 31.6 \\
& $>6$ & 16 & 4.3 \\
\hline Sum of clinical courses & $\leq 5$ & 140 & 37.2 \\
ever taught & $6-10$ & 144 & 38.3 \\
& $\geq 11$ & 92 & 24.5 \\
\hline
\end{tabular}

Abbreviations: BSc, Bachelor of Science degree; MSc, Masters of Science degree. 
(midwifery, nurse, public health officer, pharmacy, and medicine) departments (Table 2).

\section{Faculty Characteristics}

Near to two-third 241 (64.1\%) of respondents give students the objective of clinical teaching for every clinical teaching session in written form. Besides, more than half 209 (55.6\%) of respondents had classroom teaching as an additional workload during their clinical teaching. Similarly, around two-fifth 156 (41.5\%) of respondents use performance-based assessment tools for assessing students' clinical learning objectively. In contrast, less than one-fifth 67 (17.8\%) of respondents use guidelines for clinical teaching.

\section{Self-Reported Attributes of Respondents Toward Clinical Teaching}

Respondents' attribute toward clinical teaching was measured by using 5-point Likert scale indicating 1 - very poor, 2 - poor, 3 - fair, 4 - good, and 5 - very good. As a result, there was no response as very poor and poor. Then, response with good and very good was condensed as good and response with the fair was kept as it was. In general, most 345 (91.8\%), 298 (79.3\%), 311 (82.7\%), 316 $(84 \%)$, and $334(88.8 \%)$ of respondents reported that they had a good interest in the midwifery profession, had good

Table 2 Clinical Teaching Site Characteristics Where Midwifery Educators of Ethiopian Public Universities Teach Clinical Courses, Ethiopia, $2019(\mathrm{~N}=376)$

\begin{tabular}{|c|c|c|c|}
\hline Variables & Category & Frequency & $\begin{array}{l}\text { Percent } \\
\text { (\%) }\end{array}$ \\
\hline Clinical teaching site & $\begin{array}{l}\text { Tertiary } \\
\text { hospital } \\
\text { Primary } \\
\text { hospital } \\
\text { Health center } \\
\text { Private clinic }\end{array}$ & $\begin{array}{l}122 \\
29 \\
201 \\
24\end{array}$ & $\begin{array}{l}32.4 \\
7.7 \\
\\
53.5 \\
6.4\end{array}$ \\
\hline $\begin{array}{l}\text { Number of students } \\
\text { per clinical unit }\end{array}$ & $\begin{array}{l}<4 \\
5-8 \\
9-12 \\
\geq 13\end{array}$ & $\begin{array}{l}19 \\
63 \\
144 \\
150\end{array}$ & $\begin{array}{l}5 \\
16.8 \\
38.3 \\
39.9\end{array}$ \\
\hline $\begin{array}{l}\text { Theoretical part } \\
\text { taught before clinical } \\
\text { teaching }\end{array}$ & $\begin{array}{l}\text { Fully taught } \\
\text { Only some }\end{array}$ & $\begin{array}{l}309 \\
67\end{array}$ & $\begin{array}{l}82.2 \\
17.8\end{array}$ \\
\hline $\begin{array}{l}\text { Resource for clinical } \\
\text { teaching }\end{array}$ & $\begin{array}{l}\text { Adequate } \\
\text { Not adequate }\end{array}$ & $\begin{array}{l}19 \\
357\end{array}$ & $\begin{array}{l}5 \\
95\end{array}$ \\
\hline
\end{tabular}

midwifery curriculum knowledge competency, had good midwifery skill competency, had good interest in clinical teaching, and had good communication skill, respectively.

\section{Effective Clinical Teaching Practice and Factors Associated with It}

More than half 198 (52.7\%) of respondents had not ECTP. From the multivariable binary logistic regression analysis, seven variables were statistically significantly associated with ECTP. Those variables were clinical teaching experience, training on HDP, clinical teaching workshop, number of students per clinical unit, provision of clinical learning objective of clinical teaching for every clinical teaching session in written form, using performance-based assessment tool for assessing students' clinical learning objectively, and interest in clinical teaching.

The odds of ECTP among midwifery educators who had 1-3 and 4-6 years of experience in clinical teaching was 3.31 and 4.72 times higher respectively compared to midwifery educators who had $\leq 1$ year of clinical teaching experience $(\mathrm{AOR}=3.31 ; 95 \% \mathrm{CI}=1.46,7.44)$ and $(\mathrm{AOR}=$ 4.72; $95 \% \mathrm{CI}=1.97,11.29)$. Similarly, the odds of ECTP among midwifery educators those were trained on HDP was 2.78 times higher compared to their counterpart (AOR 2.78; $95 \% \mathrm{CI}=1.61,4.82$ ).

The odds of ECTP among midwifery educators who had clinical teaching workshops was 4 times higher compared to midwifery educators who did not have clinical teaching workshops $(\mathrm{AOR}=4 ; 95 \% \mathrm{CI}=1.98,8.1)$. Also, the odds of ECTP among midwifery educators who teach 5-8 and 9-12 students per clinical unit was 3.71 and 2.39 times higher respectively compared to midwifery educators who teach $\geq 13$ students per clinical unit (AOR 3.71; $95 \% \mathrm{CI}=1.664,8.265)$ at $(\mathrm{p}$-value $=0.001)$ and $(\mathrm{AOR}$ $2.39 ; 95 \% \mathrm{CI}=1.26,4.54)$.

Moreover, the odds of ECTP among midwifery educators who provide clinical learning objectives (CLO) in written form to students for every clinical teaching session was 4.74 times higher compared to midwifery educators who did not provide it for students (AOR 4.74; 95\% $\mathrm{CI}=2.43$, 9.26). Furthermore, the odds of ECTP among midwifery educators that use performance-based assessment (PBA) tool for assessment of clinical learning of students' was $82 \%$ higher compared to those who did not use it to assess clinical learning of students (AOR 1.82; $95 \% \mathrm{CI}=1.05,3.16$ ). Lastly, the odds of ECTP among midwifery educators those had good interest in clinical 
teaching was 8.63 times higher compared to midwifery educators those had a fair interest in clinical teaching (AOR 8.63; 95\% CI=2.91, 25.56) (Table 3).

\section{Discussion}

This study found that less than half 178 (47.3\%) of midwifery educators of Ethiopian Public Universities had effective clinical teaching practice. Clinical teaching workshop, training on HDP, clinical teaching experience, number of students a clinical educator teach per clinical unit, using performancebased assessment tool for assessing clinical learning of students, provision of the objective of clinical learning in written form to students for every clinical teaching session, and interest in clinical teaching were found to be factors associated with effective clinical teaching practice.

As indicated above, less than half of the respondents of the current study had ECTP. This finding is higher than the result of a study done in Lusaka Zambia in which only one-fourth $30(24.2 \%)$ of participants had performed good clinical teaching skills. ${ }^{23}$ The reason for the discrepancy may be due to the difference regarding the professional qualification of participants as two-thirds 81 (65.3\%) of participants in Lusaka Zambia had a certificate in midwifery which is equivalent to diploma level but in the current study about three-fourth, 278 (73.9\%) of participants had MSc and even the rest one-fourth 98 (26.1\%) had BSc which is higher than that of Lusaka Zambia.

Even if the result of the current study is better than the finding of the study in Zambia, it is very far below the ideal expectation as there should be $100 \%$ ECTP. Contextually, there are substantial contributing factors for such low ECTP. Among others, only two-fifths (42.8\%), and one-fourth $(25.8 \%)$ of respondents were trained on HDP and had clinical teaching workshops respectively that would have been resulted in better ECTP. Besides, $44.2 \%$ (166) of respondents teach clinical courses in overcrowded clinical teaching sites by students from other departments and 95\% (357) of them teach in an area where there is no adequate resource for clinical teaching.

In the current study, years of experience in clinical teaching were found to be positively associated with ECTP. This result is consistent with the result of the study done in six Universities of North America where the effect of teacher experience on improving ECTP was strongest during the first few years of teaching. ${ }^{21}$ Similarly, in the current study, training on a higher diploma in the teaching profession and clinical teaching were found to promote the provision of ECTP. This finding is consistent with the result of a study done in Malaysia where in-service training had improved ECTP by empowering teachers to be systematic and logical. ${ }^{19}$

The current study showed that teaching 5-12 students per clinical unit is positively associated with ECTP. This result is consistent with the result of a study done at the Department of Midwifery in Mekelle University that suggested 5-8 students per clinical unit to effectively provide clinical education. ${ }^{24}$ In opposite, the result of a study done at Oman Nursing College suggested four students per clinical teaching unit maximize ECTP. ${ }^{9}$ However, two fifth $150(39.9 \%)$ of respondents of the current study taught $\geq 13$ students per clinical unit that probably contributed to the achievement of less than half (47.3\%) ECTP.

Moreover, the current study revealed that the provision of the objective of clinical learning in written form to students for every clinical teaching session promoted the ECTP. This finding is consistent with the existing knowledge that clinical educators should give to students clinical competencies for every clinical teaching session in written form and should clarify it for students until they clearly understood it to foster ECTP. ${ }^{7}$ This is because the learning objective enables learners to focus their approach efficiently to attain their learning outcome.

The current study showed using performance-based assessment tool for the assessment of clinical learning of students' increased the chance of ECTP by educators. This finding is consistent with the result of a study done in Iran at Guilan University where using a clear evaluation system affected effective clinical teaching practice by $62.1 \%{ }^{20}$ Possibly because educators who use a performance-based assessment tool probably make their teaching approach inline with what students were going to be assessed on and also student themselves may stimulate the educators to teach them focusing on what they were going to be assessed on. Besides, using a performance-based assessment tool allows identifying students' areas of weakness and strength that would enable clinical educators to align their teaching approach with students' level of readiness that would enable them to practice effective clinical teaching.

Midwifery educators' interest in clinical teaching was found to increase the chance of ECTP by clinical educators. This finding is consistent with the finding of a study done at Guilan University in Iran where interest in clinical teaching affected ECTP by $93.9 \% .^{20}$ This finding might indicate that interest in clinical teaching affects ECTP as it 
Table 3 Bivariate and Multivariable Analyses of Factors Associated with Effective Clinical Teaching Practice Among Midwifery Educators of Ethiopian Public Universities, Ethiopia, 2019 ( $N=376)$

\begin{tabular}{|c|c|c|c|c|c|c|}
\hline \multirow[t]{2}{*}{ Variables } & \multirow[t]{2}{*}{ Category } & \multicolumn{2}{|l|}{ ECTP } & \multirow[t]{2}{*}{ COR $(95 \% \mathrm{Cl})$} & \multirow[t]{2}{*}{ AOR $(95 \% \mathrm{Cl})$} & \multirow[t]{2}{*}{$\mathbf{P}$} \\
\hline & & No (N, \%) & Yes (N, \%) & & & \\
\hline \multirow[t]{4}{*}{ Experience in clinical teaching (in years) } & $\leq 1$ & $66(81.5)$ & $15(18.5)$ & 1 & 1 & \\
\hline & $1-3$ & $86(53.7)$ & $74(46.3)$ & $3.79(1.99,7.19)$ & $3.31(1.47,7.44)$ & 0.004 \\
\hline & $4-6$ & $4 I(34.5)$ & $78(65.5)$ & $8.37(4.26,16.46)$ & $4.72(1.97,11.29)$ & 0.000 \\
\hline & $>6$ & $5(31.3)$ & II (68.7) & $9.68(2.93,32.03)$ & $3.68(0.79,17.19)$ & 0.098 \\
\hline \multirow[t]{2}{*}{ Trained on HDP } & No & $150(69.8)$ & $65(30.2)$ & 1 & 1 & \\
\hline & Yes & $48(29.8)$ & $1 \mathrm{I} 3(70.2)$ & $5.43(3.48,8.48)$ & $2.78(I .6 I, 4.82)$ & 0.000 \\
\hline \multirow[t]{2}{*}{ Attended workshop } & No & $176(63.1)$ & $103(36.9)$ & 1 & 1 & \\
\hline & Yes & $22(22.7)$ & $75(77.3)$ & $5.83(3.42,9.93)$ & $4(1.98,8.05)$ & 0.000 \\
\hline \multirow[t]{4}{*}{ Student per clinical unit } & $\leq 4$ & $13(68.4)$ & $6(31.6)$ & $0.69(0.25,1.92)$ & $1.15(0.33,4.08)$ & 0.827 \\
\hline & $5-8$ & $21(33.3)$ & $42(66.7)$ & $3(1.62,5.56)$ & $3.71(1.66,8.27)$ & 0.001 \\
\hline & $9-12$ & $74(51.4)$ & $70(48.6)$ & $1.42(0.89,2.25)$ & $2.39(1.26,4.54)$ & 0.008 \\
\hline & $\geq 13$ & $90(60)$ & $60(40)$ & 1 & 1 & \\
\hline \multirow[t]{2}{*}{ Give CLO for learner } & No & $84(62.2)$ & $5 \mathrm{I}(37.8)$ & 1 & I & \\
\hline & Yes & II4(47.3) & $127(52.7)$ & $1.84(1.19,2.82)$ & $4.74(2.43,9.26)$ & 0.000 \\
\hline \multirow[t]{2}{*}{ Using PBA tool } & No & $135(61.4)$ & $85(38.6)$ & I & 1 & \\
\hline & Yes & $63(40.4)$ & $93(59.6)$ & $2.34(1.54,3.57)$ & $1.82(1.05,3.16)$ & 0.034 \\
\hline \multirow[t]{2}{*}{ Interest in teaching } & Fair & $55(91.7)$ & $5(8.3)$ & 1 & 1 & \\
\hline & Good & $143(45.3)$ & $173(54.7)$ & $|3.3|(5.19,34.13)$ & $8.63(2.91,25.56)$ & 0.000 \\
\hline
\end{tabular}

Abbreviations: CLO, clinical learning objective; HDP, higher diploma in teaching profession; PBA, performance based assessment.

is universal that without having interest it is impossible to achieve whatever is needed to be achieved. ${ }^{25}$

\section{Strengths and Limitation}

This study was conducted at a national level using a large sample size and probability sampling method to minimize selection bias and to ensure its generalizability. To minimize information bias: pretested, valid, and reliable questionnaire was used to collect data. Study participants were also limited using exclusion criteria to those who were on clinical teaching practice at the data collection period to reduce recall bias. Similarly, the objective of the study was clearly described for study participants, and confidentiality of their response was assured to enable participants to be free of the fear of social desirability bias and to encourage them to provide their genuine response. Also, data quality was maintained throughout and an appropriate statistical analysis method was used with strong model goodness of fit test. However, it was not without limitation. It was better to support the finding of this study by data collected by an observational method to further strengthen the truthfulness of the findings. Besides, periodic evaluation of teachers' competencies and students' scores for each teacher was better to be considered.

\section{Conclusion}

Less than half of midwifery educators of Ethiopian Public Universities had effective clinical teaching practice. Several factors were found to have an effect on ECTP among Ethiopian midwifery educators. Clinical teaching experience, training on a higher diploma in the teaching profession, attending clinical teaching workshop, the number of students a clinical educator teach per clinical unit, providing objectives of clinical learning in written form to students for every clinical teaching session, using performance-based assessment tool for assessing students' clinical learning and interest in clinical teaching of educators were positively associated with ECTP. Therefore, the higher diploma in the teaching profession and clinical training for educators should be strengthened to deliver clinical education effectively. Besides, the educators and the department should adhere to the guideline for ECTP such as limiting the class size to the standard for the provision of effective clinical teaching. 


\section{Abbreviations}

BSc, Bachelor of Science degree; CLO, clinical learning objective; ECT, effective clinical teaching; ECTP, effective clinical teaching practice; EPU, Ethiopian Public Universities; HDP, higher diploma in teaching profession; MEP, Midwifery Education Program; MSc, Masters of Science degree; PBA, performance-based assessment.

\section{Acknowledgments}

The authors are very grateful to Mekelle University for the financial support of this study and the Department of Midwifery for its mentorship. We are also thankful to the study participants for their willingness and commitment to participate in this study.

\section{Author Contributions}

All authors made a significant contribution to the work reported throughout. This include contribution in the conception of the research idea, study design, execution, acquisition of data, analysis and interpretation, drafting, revising, critically reviewing the article; gave final approval of the version to be published; have agreed on the journal to which the article has been submitted; and agree to be accountable for all aspects of the work.

\section{Funding}

This study was done with funds provided by Mekelle University merely for data collection purposes as for the MSc thesis.

\section{Disclosure}

The authors declare that they have no conflicts of interest for this work.

\section{References}

1. International confederation of midwives. International Definition of the Midwife. Hague, Netherlands; 2011. Available from: https:/inter nationalmidwives.org/assets/files/definitions-files/2018/06/engdefinition_of_the_midwife-2017.pdf. Accessed February 5, 2019.

2. Baker K "Senior nursing students perception of clinical teacher behavior" (2012). Nursing Theses and Capstone Projects. 95. [Internet]; 2012. Available from: https://digitalcommons.gardner-webb.edu/nur sing_etd/95. Accessed January 17, 2019.

3. Sezer H. How should clinical education be in nursing education? J Nurs Res Pr. 2018;2(1):15.

4. Weldu M, Gedamu A. Perception of midwifery students towards characteristics of clinical teachers at public Universities, Tigray, Ethiopia, 2016. J Women Heal Care. 2018;7(4):1-6.

5. Martin E, Gumabay D. Caring behaviors of clinical instructors during nursing students' related learning experience: a basis for enhancing student-mentor relationship. Asia Pacific J Multidiscip Res. 2017;5 (1):84-93.
6. Kikukawa M, Stalmeijer R, Emura S, Roff S, Scherpbier A. An instrument for evaluating clinical teaching in Japan: content validity and cultural sensitivity. BMC Med Educ. 2014;14(179):1-8. doi:10.1186/1472-6920-14-179

7. Magnier K, Dale V. Challenges and responsibilities of clinical teachers in the workplace: an ethnographic approach. JVME. 2014;41 (2):155-161. doi:10.3138/jvme.0813-111R1

8. Gaberson K, Oermann M, Shellenbarger T Clinical teaching strategies in nursing [Internet]. New York: springer publishing company; 2015. Available from: www.repository.embuni.ac.ke/.../ ClinicalTeachingStrategiesinNursing. Accessed April 5, 2019.

9. Madhavanprabhakaran G, Shukri R, Hayudini J, Narayanan S. Undergraduate nursing students' perception of effective clinical instructor: oman. Int J Nurs Sci. 2013;3(2):38-44.

10. Federal Ministry of Education. The Federal Democratic Republic of Ethiopia. Education Sector Development Programme V (ESDP V) 2015/16-2019/2020 [Internet]. Addis Ababa; 2015. Available from: https://planipolis.iiep.unesco.org/sites/planipolis/files/ressources/ethio pia_esdp_v.pdf. Accessed January 17, 2019.

11. United Nations. Transforming our world: the 2030 Agenda for Sustainable Development. New York; 2015. Available from: https:// sustainabledevelopment.un.org/content. Accessed March 10, 2021.

12. Federal Ministry of Education. The Federal Democratic Republic of Ethiopia. List of Ethiopian Public Universities [Internet]; 2013. Available from: https://photos.state.gov/.../ethiopia/.../ ListofEthiopianPublicUniversities. Accessed February 10, 2019.

13. FDRE. Universities intake capacity for 2011 Ethiopian calendar academic year [Internet]. Addis Ababa: Ethiopian Federal ministry of education; 2018. Available from: http://www.neaea.gov.et/wpcontent/uploads/2018/09/Intake-Capacity-for-2011-Entry.pdf. Accessed February 10, 2019.

14. Yigzaw T, Ayalew F, Kim Y, et al. How well does pre-service education prepare midwives for practice: competence assessment of midwifery students at the point of graduation in Ethiopia. BMC Med Educ. 2015;15(130):1-10.

15. Knox JE, Mogan J. Important clinical teacher behaviors as perceived by university nursing faculty, students and graduates. $J A d v$ Nurs. 1985;10:25-30. doi:10.1111/j.1365-2648.1985.tb00488.x

16. Fikre R. Assessment of Factors Affecting Clinical Practice Competency of Undergraduate Health Science Students in Hawassa University. $J$ Heal Med Nurs. 2016;22 (2422-8419):11-18.

17. Reising D, James B, Morse B. Student perceptions of clinical instructor characteristics affecting clinical experiences. Natl Leag Nursing. 2018;39(1):4-9.

18. Jimma University. Jimma University Revised Senate Legislation: Focusing on Academic and Technical Staff Development, Roles and Responsibilities. Jimma, Ethiopia: Jimma University; 2018.

19. Mohd Z. The need for in-service training for teachers and it's effectiveness in school. Int J Innov Educ Res. 2014;2(11):1-9. doi:10.31686/ijier.vol2.iss11.261

20. Firoozehchian F, Taheri Z, Dadgaran I. Nursing-Midwifery students and teachers' views of effective factors in clinical education. Procedia Soc Behav Sci. 2012;47:1832-1837. doi:10.1016/j. sbspro.2012.06.908

21. King J The impact of teacher experience examining the evidence and policy implications [Internet]; 2010. Available from: https://eric.ed. gov/?id=ED511988\%0A. Accessed May 31, 2019.

22. Bharj K, Cert I, Embo M. Factors affecting quality of midwifery student learning in the workplace: results of two ICM congress workshops. Midwifery. 2018;62:116-118. doi:10.1016/j. midw.2018.03.018

23. Bweupe N, Ngoma C, Sianchapa B. Clinical supervision of midwifery students at the University teaching hospital school of Nursing and Midwifery in Lusaka, Zambia. Open J Nurs. 2018;8(2):372-389. doi:10.4236/ojn.2018.86030 
24. Tamrat A Educational processes and practices of undergraduate midwifery clinical teaching in Mekelle University [Internet]. Addis Ababa University; 2018. Available from: http://etd.aau.edu.et/bit stream/handle/123456789/13492/AzebTamrat.pdf?. Accessed April 12,2019
25. Harackiewicz J, Hulleman C. The importance of interest: the role of achievement goals and task values in promoting the development of interest. Soc Personal Psychol Compass. 2010;4(1):42-52. doi:10.1111/j.1751-9004.2009.00207.x

\section{Publish your work in this journal}

Advances in Medical Education and Practice is an international, peerreviewed, open access journal that aims to present and publish research on Medical Education covering medical, dental, nursing and allied health care professional education. The journal covers undergraduate education, postgraduate training and continuing medical education including emerging trends and innovative models linking education, research, and health care services. The manuscript management system is completely online and includes a very quick and fair peer-review system. Visit http://www.dovepress.com/testimonials.php to read real quotes from published authors. 